\title{
Age and Gender in Relation to Colorectal Cancer in Najef Province: A Histopathological Study
}

\author{
Homady M. H*1, Juma, A. S. M', Ubeid, M. H², Salih T. S ${ }^{1}$, Al-Jubori, M, $\mathbf{M}^{3}$ \\ ${ }^{1}$ Department of Biomedical Sciences, College of Science, Cihan University-Erbil, Kurdistan - Iraq. \\ ${ }^{2}$ Department of General Biology, College of Science, Cihan University-Erbil, Kurdistan - Iraq. \\ ${ }^{3}$ College of Medicine, Babylon University, Iraq.
}

*Corresponding Author: Homady M. H, Department of Biomedical Sciences, College of Science, Cihan University-Erbil, Kurdistan - Iraq. Received date: January 29, 2021; Accepted date: February 19, 2021; Published date: February 24,2021

Citation: Homady M. H.; Juma, A. S. M.; Ubeid, M. H.; Salih, T. S. Al-Jubori, M, M. (2021) Age and Gender in Relation to Colorectal Cancer in Najef Province: A Histopathological Study. Journal of Clinical and Laboratory Research. 2(1) DOI: 10.31579/2768-0487/006

Copyright: (C2021 Homady M. H. This is an open-access article distributed under the terms of the Creative Commons Attribution License, which permits unrestricted use, distribution, and reproduction in any medium, provided the original author and source are credited.

\begin{abstract}
Colorectal cancer (CRC), which is also referred to colorectal adenocarcinoma, occurs when the growth of cells goes out of control in the colon or rectum. A number of histological colorectal carcinoma are listed, such as mucinous, signet ring cell, and moderately differentiated adenocarcinoma. The present study included fifty tissue blocks (16 females and 34 males) of patient groups with CRC and thirty five tissue blocks of colon tissue (ulcerative colitis) which were used as control group. The mean age of patients group was $51.44 \pm 16.67$ years. The majority of patients with colonic carcinoma were above the age of 40 , accounting for $80 \%$, while $20 \%$ of cases were below the age of 40 years. A recto-sigmoid location is the most common site for colonic tumors accounting for $60 \%$. Grade of tumor was well differentiated in 56\%, and the following features were observed: The tissue appears with multi-layering, back to back arrangement (little intervening stroma), loss of polarity, loss of goblet cells, and invasion of stroma and presence of nuclear criteria of malignancy: hyperchromatism, high N/C ratio visible nucleoli and abnormal mitosis. The present results also showed that in grade I lesion, most of tumor retains glandular pattern, moderately differentiated in $28 \%$, and tumor is nearly equally composed of glandular and solid patterns. However the poorly differentiated was $16 \%$ with same cellular criteria of malignancy but almost all the tumor was composed of solid areas. The present findings divided the stage of tumor patients into: $22 \%$ stage I; $66 \%$ stage II, and $12 \%$ stage III.
\end{abstract}

Keywords: colorectal; age; gender; carcinoma; malignancy

\section{Introduction}

Colorectal cancer $(\mathrm{CRC})$ is the $2^{\text {nd }}$ most common cancer in females and the $3^{\text {rd }}$ most common cancer in males (Ferlay et al., 2013). This disease is the most common malignancy in men with 75 years of age and over. It has been concluded that over one million people develop CRC annually, where the disease specific mortality rate being in the developed world (Cunningham et al., 2010).

Lifestyle, genetic and environmental factors were found to be of some of the factors that make CRC a multifactorial disease. Even though CRC could be hereditary and non-hereditary, however, the non-hereditary type is the most common and mainly caused by somatic mutations in response to environmental factors. Colorectal tumours appear with a wide variety of abnormal tissue growths (malignant tumours) ranging from benign tumours to infiltrating cancer, and are primarily tumours that developed from epithelial cells (namely, adenomas or adenocarcinomas). Genetic change in the epithelial cells of colon is considered the essential process in the etiology of colorectal carcinoma. However, liver and lung distant metastases in CRC are common (Zarychanski et al., 2007). The peak incidence of CRC is at the age of 60 to 70 years and fewer than $20 \%$ of cases occur before age of 50, males being slightly more affected than females. Most CRC occurs sporadically, where $25 \%$ of the patients were found to have a family history of the disease, suggesting that shared genes and environment may contribute to the disease (Jasperson et al., 2010). Rates of CRC increase with environmental factors that may represent risk factors (Migliore et al., 2011). Diets high in total fat and meat, both red and white meats, appear to be associated with developing adenomatous polyps and an increased incidence of CRC risk (Meyer \& White, 1993; Michels et al., 2000). The use of some drugs and supplements, nonsteroidal anti-inflammatory diseases (NSAIDs), estrogens, folic acid, and calcium might prevent the development of CRC (Terry et al., 2001; Church \& Simmang, 2003).

The CRC under the various types of adenocarcinoma is: mucinous coiled adenocarcinoma (>50 mucinous), small-cell (oat cell) carcinoma, squamous cell carcinoma, signet-ring carcinoma, adenosquamous carcinoma, medullary carcinoma, and undifferentiated carcinoma (Hamilton et al., 2000). A malignant epithelial tumor is the most common adenocarcinoma, originating from glandular epithelium of the colorectal mucosa. CRC are adenocarcinoma originating from epithelial cells of the colorectal mucosa and represent over 90\% (Hamilton et al., 2010). Glandular formation is what characterizes conventional adenocarcinoma, which is the basis for histological tumor grading. More than $95 \%$ of the tumor is gland forming in well differentiated adenocarcinoma. 50-95\% of moderately differentiated adenocarcinoma shows gland formation. Poorly 
differentiated adenocarcinoma is mostly solid with less than $50 \%$ gland formation (Compton, Fielding, et al., 2000; Compton, Committee, et al., 2000). Large glandular structure with pools of extra cellular mucin is typical of mucinous adenocarcinoma. Many mucinous adenocarcinomas occur in patients with hereditary non polyposis CRC (HNPC or lynch syndrome) (Leopoldo et al. 2008). A prominent intra cytoplasmic mucin vacuole that pushes the nucleus to the periphery is characteristic of signet ring cell (Kang et al., 2005; Makino et al., 2005; Chen et al., 2010).

The incidence of CRC rates are the highest in Africa and Americans (Murphy et al., 2011) in addition to the overall mortality (Wong, 2010) when compared to white male and female patients. Etiologic factors could be the cause of these differences, such as smoking or diabetes mellitus (Alexander et al., 2007). The overall life time risk of CRC for men and women is similar numerically, even though most studies have shown an increased risk for men regarding advanced colorectal neoplasia as well as CRC (Roy \& Bianchi, 2009; Zisman et al., 2006). The American Cancer Society (2015) concluded that a person can develop CRC at any age, the risk being increased greatly with age. In fact, more than $90 \%$ of colorectal cases are diagnosed in patients over the age of 50.

Therefore, the aim of the present study was to clarify the relation of age and gender with the different types CRC in Najef province.

\section{Material and Methods}

The present study was conducted in the laboratories of Molecular Biology, Faculty of Science, Kufa University and Al-Sadar Teaching
Hospital in Al-Najef province. Fifty tissue blocks embedded in paraffin wax of colorectal cancer (CRC) (16 female and 34 males) were obtained as patients group. Thirty five other tissue blocks also embedded in paraffin wax from colon (ulcerative colitis) were collected randomly during the collection of malignant samples age and sex being matched, used as a control group. Five $\mu \mathrm{m}$-thick sections were obtained from paraffin embedded tissues. These sections were processed and stained by using Haematoxylin and Eosin, the method described by Al-Jubori, (2015). Digital analysis was performed using image J software, and data were analyzed using two software programs, (SPSS) version 16 and Microsoft Office Excel (2010). For purpose of presentation, numeric variables were expressed in the form of mean + SD (standard deviation). Mean values were compared using independent samples t-test. Chi-square test was used to study association between any two categorical variables. Results

Age Mean and Age Range in Patients and Control Groups:

In the present study, the mean age of patients was $51.44 \pm 16.67$ years and the median was 52 years, whereas the age range in patients group was from 21 years through to 85 years. The mean age of control group was $45.86 \pm 15.73$ and median age was 49 years, whereas the age range in control group was from 10 to 65 years.

The majority of patients with colonic carcinoma were more than 40 years of age, accounting for $80 \%$, while $20 \%$ of cases were below the age of 40 , fifteen cases out of $50(30 \%)$ were between the age of 50-59 years, (table 1 and figure 1).

\begin{tabular}{|c|c|c|c|c|}
\hline \multirow[b]{2}{*}{ Age Interval (years) } & \multicolumn{2}{|c|}{ Control } & \multicolumn{2}{|c|}{ Colonic Carcinoma } \\
\hline & No. & $\%$ & No. & $\%$ \\
\hline $10-19$ & 3 & 8.57 & 0 & 0.00 \\
\hline $20-29$ & 3 & 8.57 & 7 & 14.00 \\
\hline $30-39$ & 3 & 8.57 & 3 & 6.00 \\
\hline $40-49$ & 9 & 25.71 & 11 & 22.00 \\
\hline $50-59$ & 6 & 17.14 & 15 & 30.00 \\
\hline $60-69$ & 11 & 31.43 & 6 & 12.00 \\
\hline $70-79$ & 0 & 0.00 & 5 & 10.00 \\
\hline$\geq 80$ & 0 & 0.00 & 3 & 6.00 \\
\hline Total & 35 & 100.00 & 50 & 100.00 \\
\hline Mean + SD & \multicolumn{2}{|c|}{$45.86+15.73$ years } & \multicolumn{2}{|c|}{$51.44+16.67$ years } \\
\hline
\end{tabular}

Table 1: Age distribution of patients with colonic carcinoma and control subjects (10 year intervals).

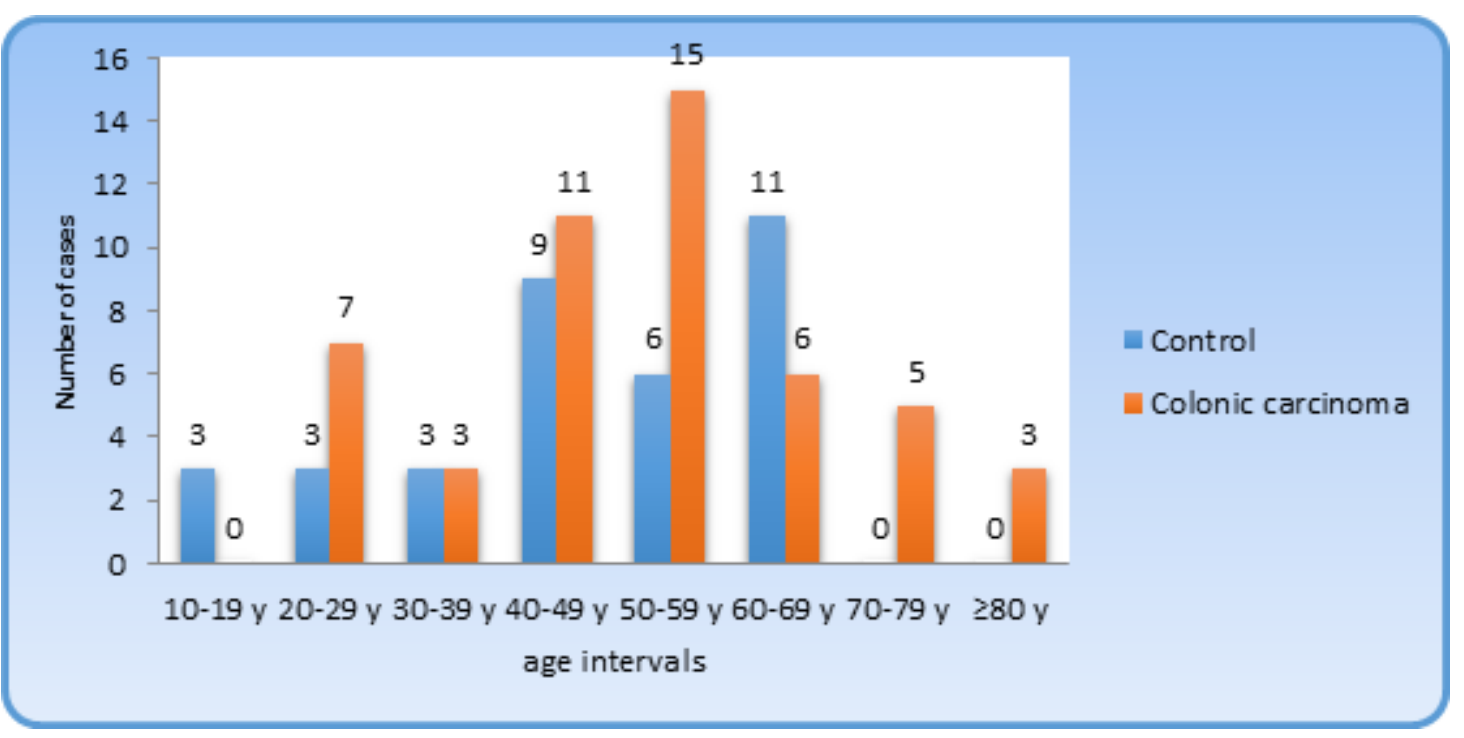

Figure 1: Distribution of patients and control subjects (10 years intervals). 


\section{Gender of Patients and Control Groups:}

The patients' group included 34 (68\%) males and $16(32 \%)$ females, while control group included 21 (60\%) males and 14 (40\%) females. Despite these minor differences in gender ratio between patients and control groups, there was no statistical difference.

The ratios of males to females in the present study were 1.5:1 and 2:1 in both control and patients groups, respectively. The mean age of male patients was $50.68 \pm 17.48$ years, whereas the mean age of female patients

\begin{tabular}{|c|c|c|c|c|c|c|c|c|}
\hline \multirow[b]{3}{*}{ Age Intervals (years) } & \multicolumn{4}{|c|}{ Control } & \multicolumn{4}{|c|}{ Colonic Carcinoma } \\
\hline & \multicolumn{2}{|c|}{ Male } & \multicolumn{2}{|c|}{ Female } & \multicolumn{2}{|c|}{ Male } & \multicolumn{2}{|c|}{ Female } \\
\hline & No. & $\%$ & No. & $\%$ & No. & $\%$ & No. & $\%$ \\
\hline $10-19$ & 2 & 9.52 & 1 & 7.14 & 0 & 0.00 & 0 & 0.00 \\
\hline $20-29$ & 2 & 9.52 & 1 & 7.14 & 6 & 17.65 & 1 & 6.25 \\
\hline $30-39$ & 2 & 9.52 & 1 & 7.14 & 1 & 2.94 & 2 & 12.50 \\
\hline $40-49$ & 4 & 19.05 & 5 & 35.71 & 8 & 23.53 & 3 & 18.75 \\
\hline $50-59$ & 5 & 23.81 & 1 & 7.14 & 11 & 32.35 & 4 & 25.00 \\
\hline $60-69$ & 6 & 28.57 & 5 & 35.71 & 3 & 8.82 & 3 & 18.75 \\
\hline $70-79$ & 0 & 0.00 & 0 & 0.00 & 2 & 5.88 & 3 & 18.75 \\
\hline$\geq 80$ & 0 & 0.00 & 0 & 0.00 & 3 & 8.82 & 0 & 0.00 \\
\hline Total & 21 & 100.00 & 14 & 100.00 & 34 & 100.00 & 16 & 100.00 \\
\hline
\end{tabular}

Table 2: Gender and age of patients with colonic carcinoma and control subjects.

These results revealed the distribution of patients according to site of tumor was as:

Thirty out of 50 patients had a recto-sigmoid tumor, accounting for $60 \%$; Seven out of 50 patients had a sigmoid tumor, accounting for $14 \%$; seven was $53.06 \pm 15.22$ years and there was no statistical difference in the mean age between male and female patients.

The mean age of male control subjects was $45.33 \pm 16.97$ years, while the mean age of females control subjects was $46.64 \pm 14.23$ years, which did not reveal any significant difference in the mean age between males and females control subjects. Performing a classification of patients by gender and age intervals revealed that most of the male patients were in the age interval of 50-59 years $(32.35 \%)$. On the other hand, the female patients revealed the higher frequency in the ages between $50-59$ years $(25 \%)$, as shown in table (2) patients had a right sided colonic tumor, accounting for $14 \%$, and six patients had a colonic tumor on the left side, accounting for $12 \%$.

It was obvious that the recto-sigmoid location is the most common site for colonic tumors in patients enrolled in the present study, as shown in figure (2).

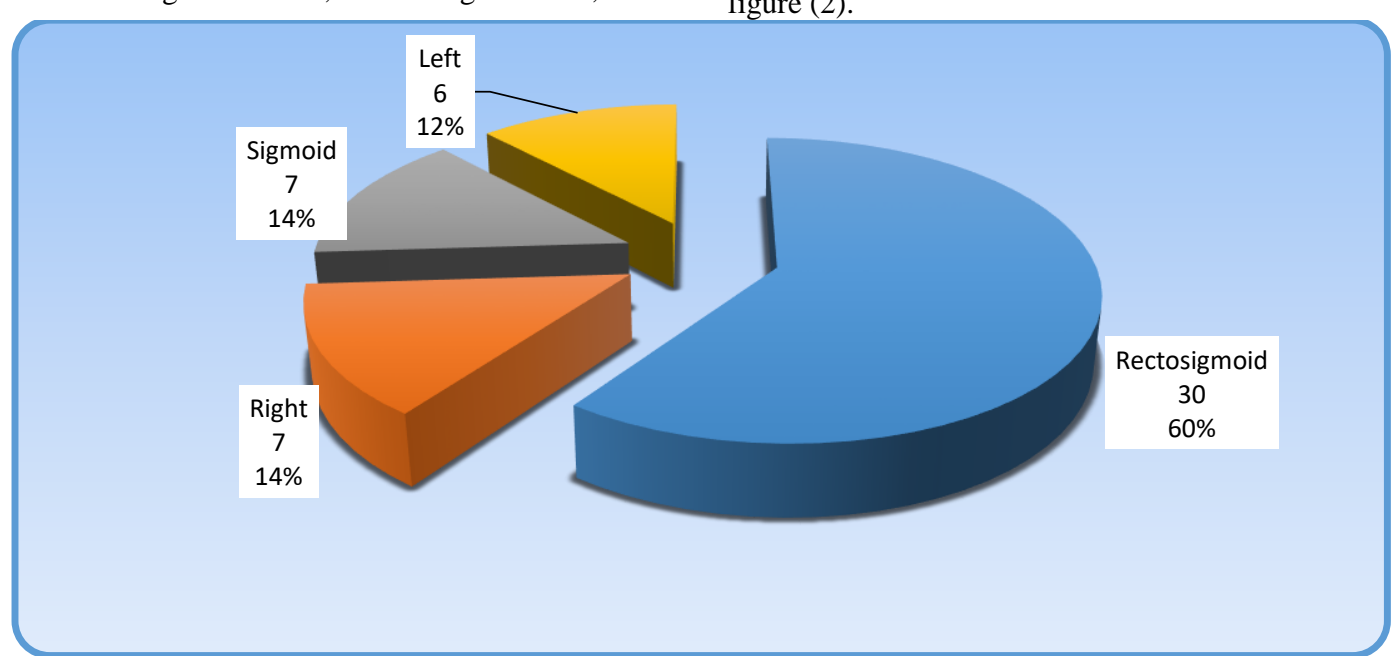

Figure (2): Site of colonic carcinoma.

The mean age of patients according to site was as follows: Patients with recto-sigmoid location had a mean age of $50.6 \pm 18.57$ years, patients with sigmoid location were $44.57 \pm 17.62$ years of age, patients with right sided

\begin{tabular}{|l|l|l|l|}
\hline Site & N & Mean & SD \\
\hline Recto-sigmoid & 30 & 50.60 & 18.57 \\
\hline Right & 7 & 52.00 & 6.45 \\
\hline Sigmoid & 7 & 44.57 & 17.62 \\
\hline Left & 6 & 63.00 & 8.34 \\
\hline Total & 50 & 51.44 & 16.67 \\
\hline
\end{tabular}

Table 3: The mean age of patients with colonic carcinoma according to site. 


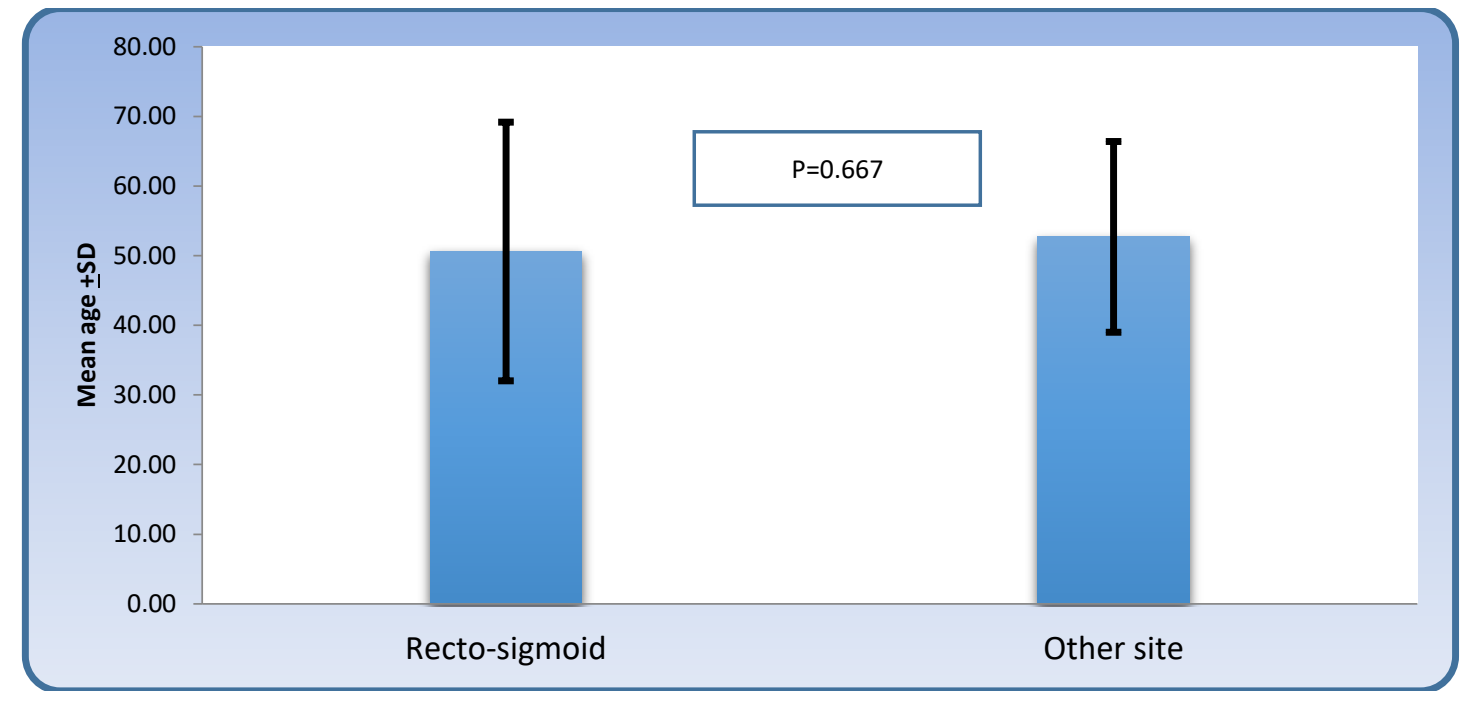

Figure 3: Comparison of mean age between those with recto-sigmoid location and others.

Classification of patients according to the site and gender: The site of colonic tumors in male patients was: $61.76 \%$ recto-sigmoid location; $17.65 \%$ right sided location; $17.65 \%$ sigmoid location and $8.82 \%$ left sided location. Additionally the site of colonic tumors in female patients was: $56 \%$ recto-sigmoid location; $18.75 \%$ sigmoid location; $18.75 \%$ left sided location and $6.25 \%$ right sided location (table 4 ).

\begin{tabular}{|l|l|l|l|l|l|l|}
\hline \multirow{2}{*}{ Site } & Male & Female & \multicolumn{3}{l|}{ Total } \\
\cline { 2 - 8 } & No. & \% & No. & \% & No. & \% \\
\hline Recto-sigmoid & 21 & 61.76 & 9 & 56.25 & 30 & 7 \\
\hline Right & 6 & 17.65 & 1 & 6.25 & 14.00 & 7 \\
\hline Sigmoid & 4 & 11.76 & 3 & 18.75 & 7.00 & 14.00 \\
\hline Left & 3 & 8.82 & 3 & 18.75 & 6 & 12.00 \\
\hline Total & 34 & 100.00 & 16 & 100.00 & 50 & 100.00 \\
\hline
\end{tabular}

Table 4: The classification of patients with colonic carcinoma according to site of tumor and gender.

Grade and Stage of Colonic Carcinoma:

The distribution of patients according to grade of tumor was:

1. Twenty eight patients (56\%) showed grade I histological pattern with well differentiated morphology. Grade I is shown in figure (5), when it is compared to normal colonic mucosa figure (4) the following features are observed: the tissue appears with multi-layering, back to back arrangement (little intervening stroma), loss of polarity, loss of goblet cells, invasion of stroma and presence of nuclear criteria of malignancy: hyperchromatism, high N/C ratio visible nucleoli and abnormal mitosis. It should be mentioned that in grade I lesion most of the tumor retains glandular pattern.

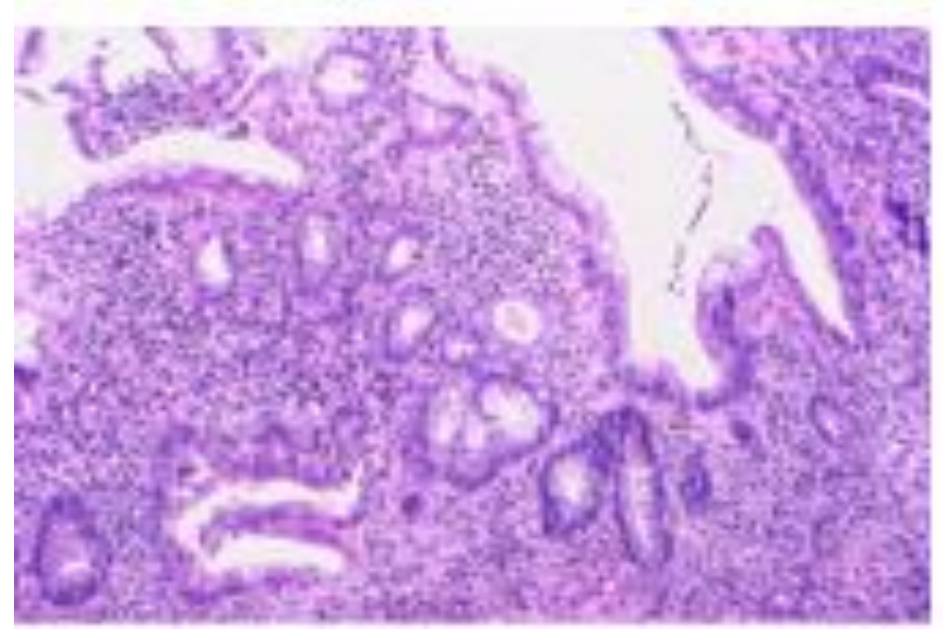

Figure 4: Histological section showing control colonic mucosa (colitis) with well-developed gland, preservation of polarity and presence of simple columnar cells; H \& E stain (10X). 


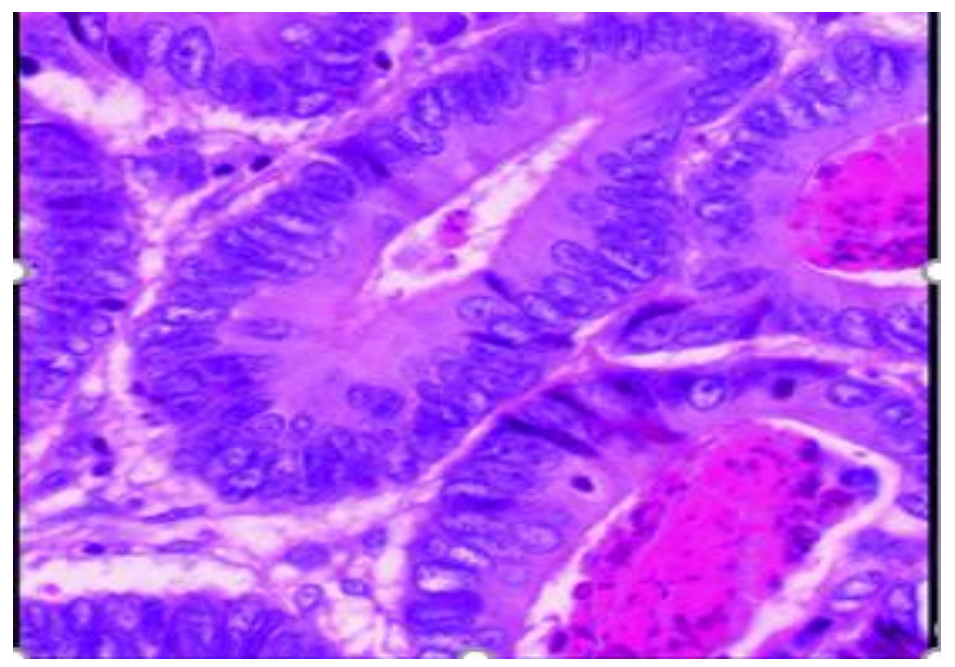

Figure 5: Histological section of colon showing well differentiated grade I adenocarcinoma with well-defined glandular pattern, multilayering, dysplastic changes, loss of polarity, and back to back arrangement; H \& E stain (40X).

2. Fourteen patients (28\%) had grade II pattern with moderately same criteria of grade I are present with tumor nearly equally composed differentiated morphology. Grade II is shown in figure (6), in which the of glandular and solid pattern.

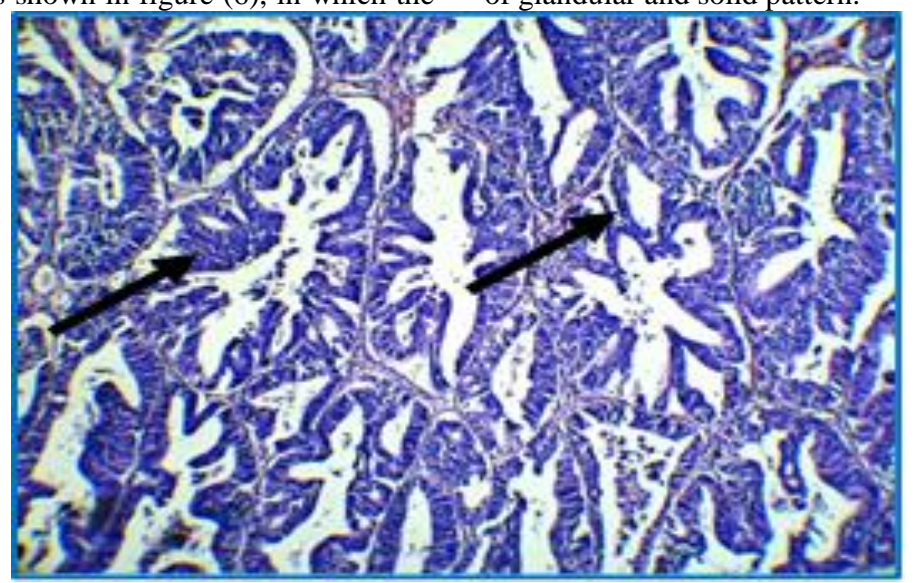

Figure 6: Histological section of colon showing moderately differentiated adenocarcinoma with mixed glandular (right arrow) and solid patterns (left arrow), dysplastic changes, back to back arrangement and loss of polarity; notice absence of goblet cells; H \& E stain (40X).

3. Eight patients (16\%) had grade III histological pattern with poorly differentiated morphology. Grade III is shown in figure (7). The figure showed same cellular criteria of malignancy but almost all the tumor is composed of solid areas.

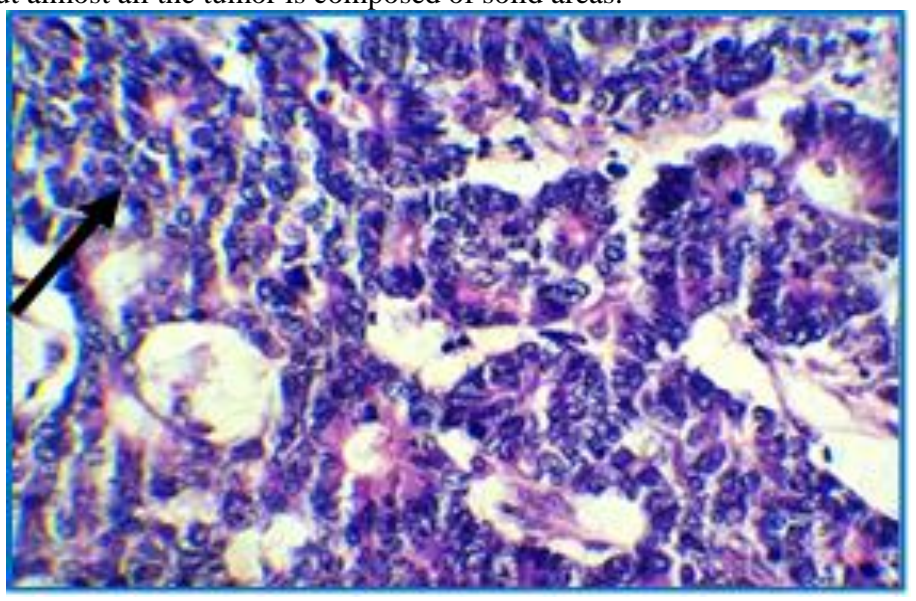

Figure 7: Histological section of colon showing poorly differentiated adenocarcinoma with almost complete solid pattern (arrow), dysplastic changes, back to back arrangement and loss of polarity; H \& E stain (40X). 
It was clear that the majority of patients exhibited well differentiated grade I tumors (table 5). According to these findings, it should be mentioned that two of the cases of colonic carcinoma were non- conventional adenocarcinoma: one of them exhibited neuroendocrine differentiation, figure (8) and the other one was mucinous figure (9).

\begin{tabular}{|l|l|l|}
\hline Grade & No. & $\%$ \\
\hline I "Well differentiated" & 28 & 56 \\
\hline II "Moderately differentiated" & 14 & 28 \\
\hline III "Poorly differentiated" & 8 & 16 \\
\hline Total & 50 & 100 \\
\hline
\end{tabular}

Table 5: The classification of patients with colonic carcinoma according to grade of tumor.

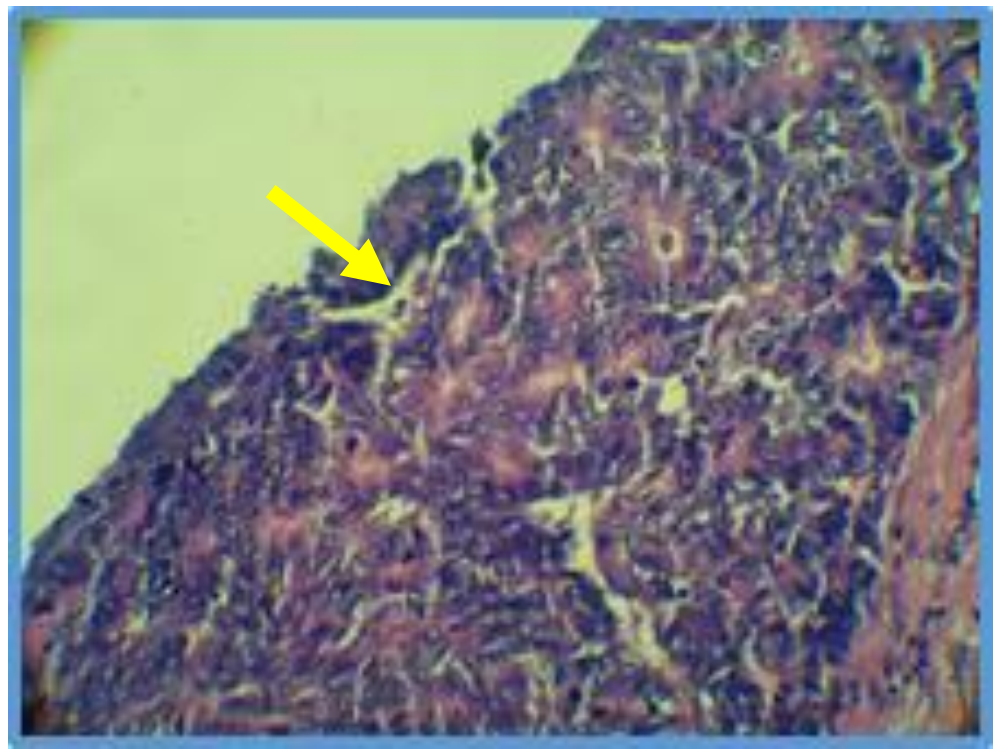

Figure 8: Histological section of colon showing neuroendocrine type adenocarcinoma with organoid pattern of growth and granular cytoplasmic appearance (arrow); H \& E stain (10X).

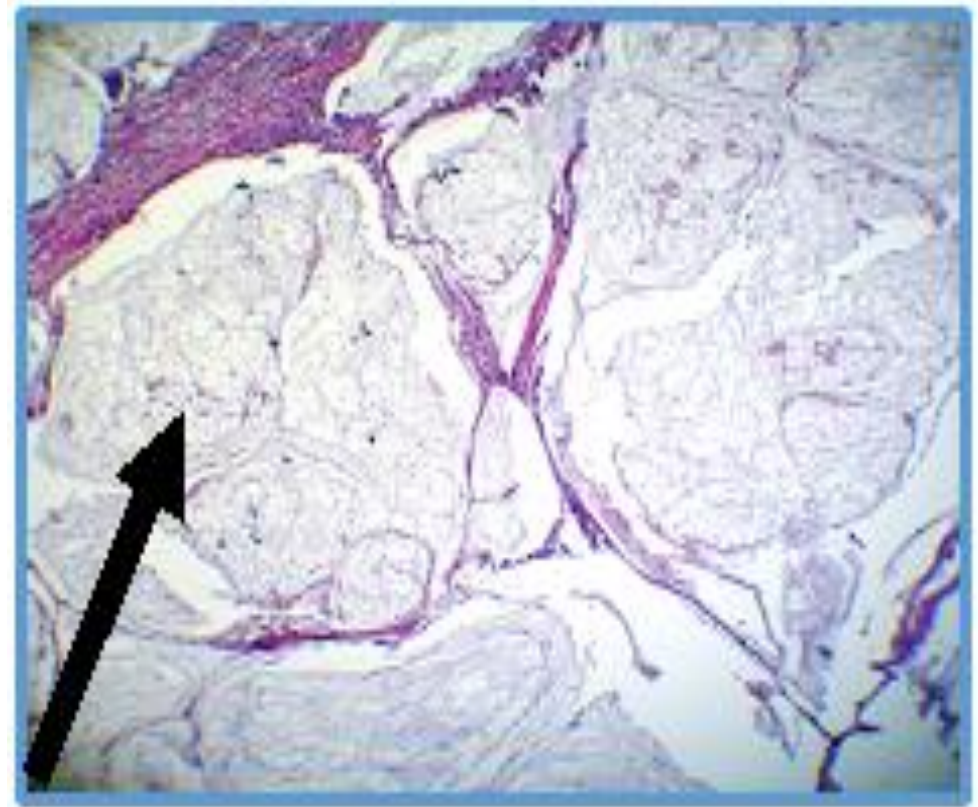

Figure 9: Colonic carcinoma (Mucinous subtype) in which there is extracellular mucin pool (arrow) with floating glandular structures (10X).

The mean age of patients with grade I histological pattern was $56.11 \pm 10.40$ years, and the mean age of patients with grade II histological pattern was $41.21 \pm 19.73$ years, whereas the mean age of patients with grade III histological pattern was $53 \pm 22.52$ years. The Spearman rank test revealed a non-significant correlation between age and grade (figure10). 


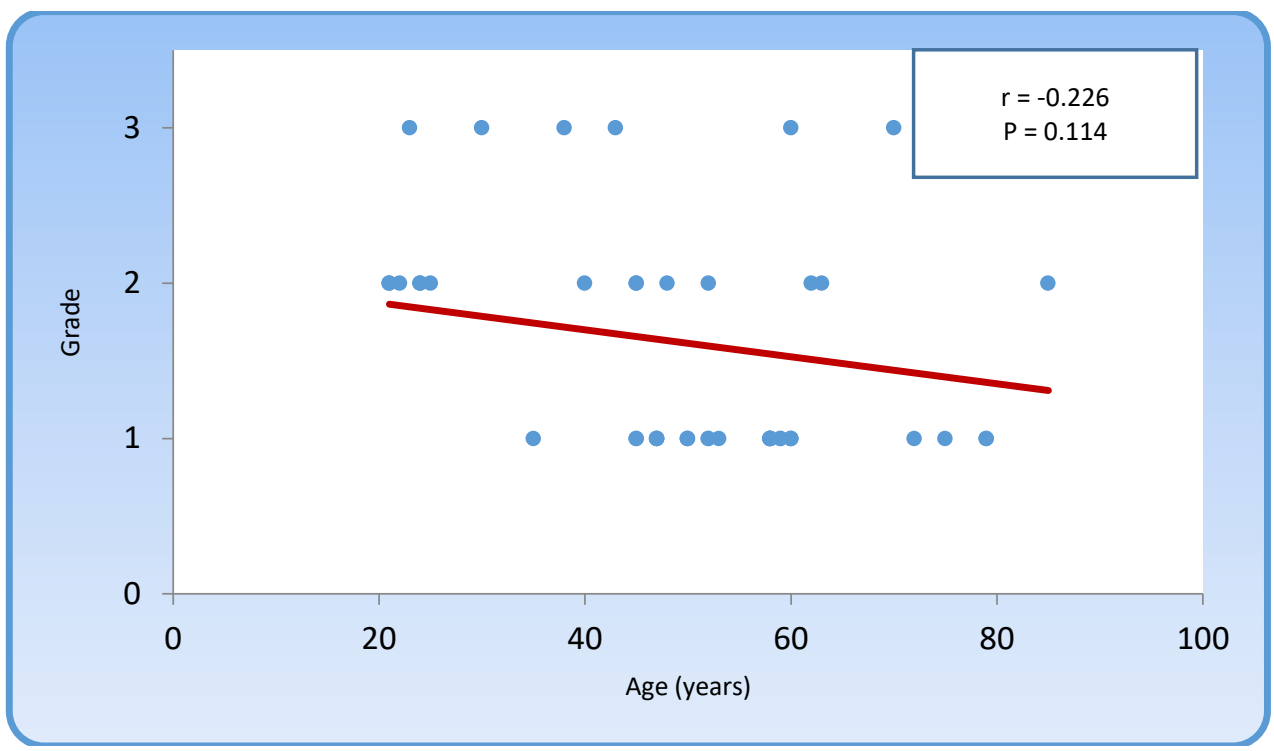

Figure 10: Spearman rank correlation between age and grade in patients with colonic carcinoma.

The distribution of patients according to grade and gender was:

1. In male patients, there were 17 cases $(50 \%)$ with grade I well differentiated histological pattern; 12 cases (35.29\%) with grade II moderately differentiated histological pattern and 5 patients $(14.71 \%)$ with grade III poorly differentiated histological pattern.

2. In female patients there were 11 patients (68.75\%) with well differentiated histological pattern; 2 patients $(12.5 \%)$ with moderately differentiated histological pattern and 3 patients $(18.75 \%)$ with poorly differentiated histological pattern.

Despite these differences in distribution of patients according to grade and gender, there was no significant association between grade and gender.

The distribution of patients according to grade and site of tumor was:

1. Patients with recto-sigmoid location showed the following grades: $53.33 \%$ grade I; $30 \%$ grade II and $16.17 \%$ grade III.

2. Patients with right sided location showed the following grades: $71.43 \%$ grade I; $14.29 \%$ grade II and $14.29 \%$ grade III.

3. Patients with sigmoid location showed the following grades: $28.57 \%$ grade I; $57.14 \%$ grade II and $14.29 \%$ grade III.
4. Patients with Left sided lesions showed the following grades: $83.33 \%$ grade I; $0 \%$ grade II and $16.67 \%$ grade III.

According to these findings there was no significant association between grade and site of tumor.

The distribution of patients according to stage of colonic carcinoma was:

1. There were 11 patients (22\%) in stage I disease.

2. There were 33 patients $(66 \%)$ in stage II disease.

3. There were 6 patients (12\%) in stage III disease.

Most of the patients were in stage II (66\%). $50.27 \pm 21.3$ years was the mean age of patients in stage I disease, $51.7 \pm 14.22$ years being the mean age of patients in stage II disease, while mean age of patients with stage III disease was $52.17 \pm 22.79$ years.

Figure (11) showed a non-significant correlation between stage of tumor and age of patients $(\mathrm{r}=0.048, \boldsymbol{P}>0.05)$.

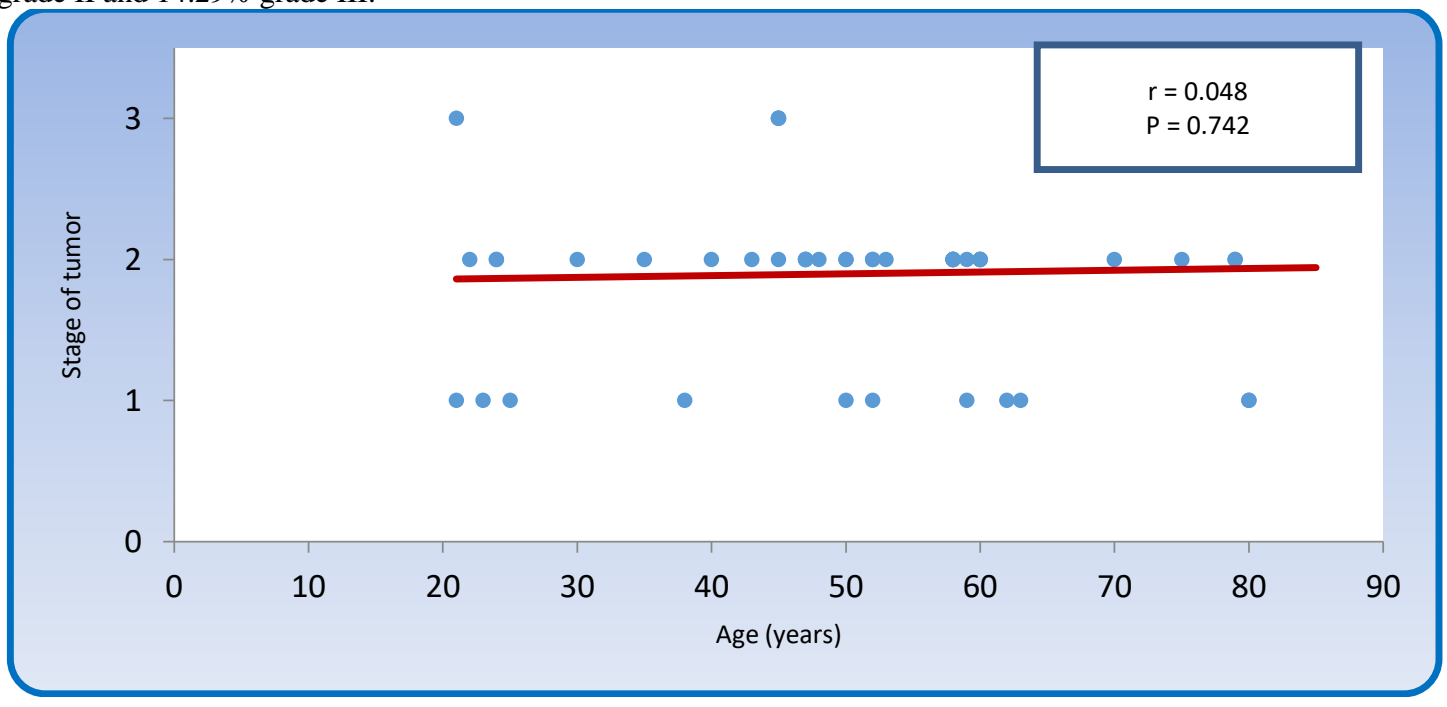

Figure 11: Spearman rank correlation between stage of disease and age of patients with colonic carcinoma 
The distribution of patients according to gender and stage of disease was:

1. Male patients showed the following stages: $32.35 \%$ stage I disease, $52.94 \%$ stage II disease and $14.71 \%$ stage III disease.
2. Female patients showed the following stages: $0 \%$ stage I, $93.75 \%$ stage II and $6.25 \%$ stage III disease.

Table (6) shows a significant association between stage of disease and gender of patients $(\boldsymbol{P}<0.05)$, in such a way that female patients are more liable to advanced stage disease than male patients.

\begin{tabular}{|l|l|l|l|l|l|l|}
\hline \multirow{2}{*}{ Stage } & \multicolumn{4}{|l|}{ Male } & Female & Total \\
\cline { 2 - 7 } & No. & $\%$ & No. & $\%$ & No. & $\%$ \\
\hline 1 & 11 & 32.35 & 0 & 0.00 & 11 & 22.00 \\
\hline $11 \& 111$ & 23 & 67.65 & 16 & 100.00 & 39 & 78.00 \\
\hline Total & 34 & 100.00 & 16 & 100.00 & 50 & 100.00 \\
\hline
\end{tabular}

Table 6: Association between stage of tumor and gender of patients with colonic carcinoma.

\section{$P=0.027 ; \quad$ Corrected $\mathrm{X}^{2}=4.885 ; \mathrm{DF}=1$}

Both grade and stage are ordinal variables; therefore Kendall's tau-b is the best statistical tool to study correlation between them. Kendall's tau-b (figure 12) yielded a non-significant negative correlation between stage of disease and grade of tumor $(\mathrm{r}=-0.240, \boldsymbol{P}>0.05)$.

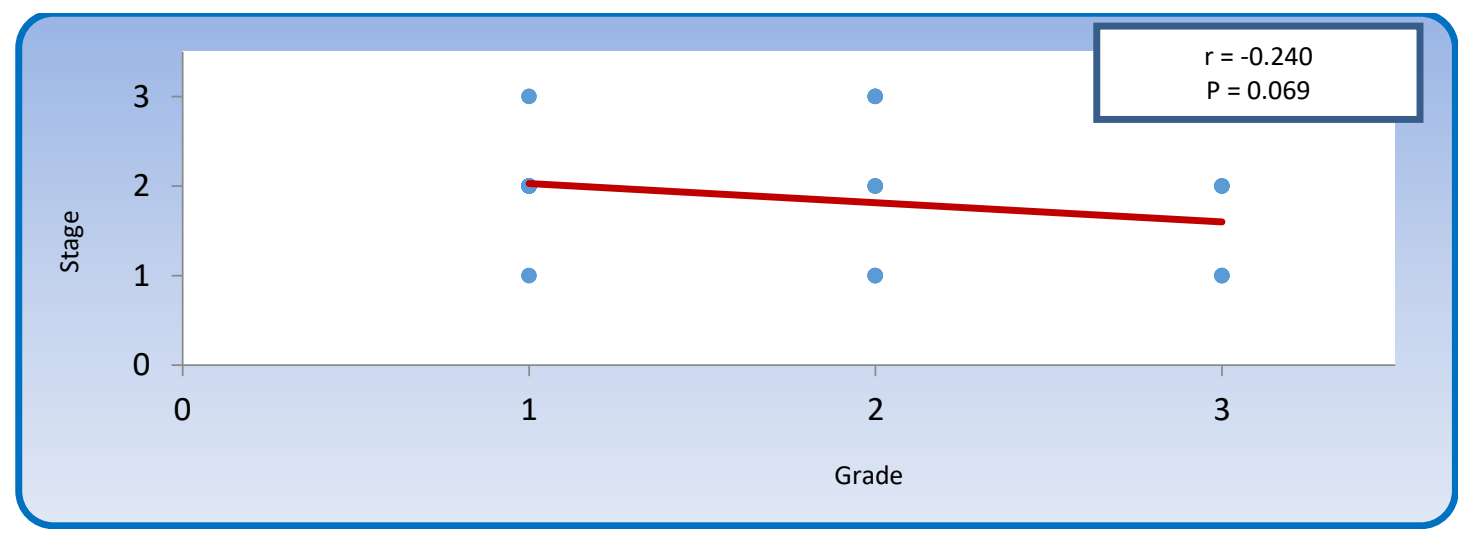

Figure 12: Kendall's tau-b correlation between grade and stage of tumor in patients with colonic carcinoma.

\section{Discussion}

The present study revealed that the mean age of patients with colorectal carcinoma was $51.44 \pm 16.67$ years and the median was 52 years while the age range was from 21 years through to 85 years. On the other hand, the majority of patients with colorectal carcinoma were more than 40 years of age, accounting for $80 \%$, while $20 \%$ of cases were less than 40 years of age. A question comes into mind is that why does colorectal carcinoma affect old age subjects more frequently than young age people?

This question can be discussed based upon the fact that carcinogenesis is a multistep process that involves a sequence of mutational events on the level of oncogenes and tumor suppressor genes. The etiology of cancer in general is attributed to two main general causes, the first one being hereditary germ line mutations in genes controlling cell cycle and growth and the second one is environmental factors.

Environmental factors, specifically the interactions between microorganisms in the colonic mucosa and food digestion products may render the colonic mucosa to become malignant due to mutations in genes. The mean age of patients with colorectal carcinoma was $53.98 \pm 14.71$ years and the median age was 55 years (Iraqi Cancer Registry, 2009). These findings are similar to the results of the present study and the minor differences are clearly due to the difference in sample size which was 701 in Iraqi Cancer Registry, while it was only 50 cases in the present study.
It was published in the Iraqi Cancer Registry (2009) that about $82 \%$ of colorectal carcinoma patients are above 40 years of age and that around $18 \%$ of patients are below the age of 40 years. Similar findings were found in the present study.

Moreover, another study conducted in Iraq stated that the mean age of patients with colorectal carcinoma was 54.5 years, a finding that solidified the result of the present study (Nidal et al., 2014). In another study also done in Iraq, the mean age of patients with colorectal carcinoma was $52.4 \pm 16.3$ years with an age range of 21-81 years (Ameen et al., 2014); these findings are comparable to those of the present results.

In a recent study done on 968 cases with colorectal carcinoma in Turkey, the mean age was $58.9 \pm 12.6$ years which is higher than that of the present study, while the age range was $18-85$ years which is comparable to the age range of the present study (Aykan et al., 2015). This younger age of Iraqi patients with carcinoma in comparison to Turkish patients may suggest the presence of an environmental carcinogenic agent in Iraq that made the progression of colorectal carcinoma faster and to appear in younger age persons.

The discussion section concerning age, which was stated above, came up with an important question that needs to be answered: why do Iraqi people develop CRC younger than nearby countries? This question can be viewed from two points of view; the first one is racial variation in age 
incidence and the second one is the presence of environmental factors in Iraqi environment that are not present in other countries, exposure to radiation for instance.

Military radiation exposure was found to be a predisposing factor to colorectal carcinoma (Kaiser et al., 2014). An increase in the incidence of birth defects was also observed, in addition to cancers, which were attributed to the use of depleted uranium in Iraq by the US army (Busby et al., 2010). Radiation exposure during the first and second Gulf war may explain in part the relatively younger age of colorectal carcinoma patients in Iraq in comparison with nearby countries.

\section{Male to Female Ratio of Enrolled Patients}

In the present study, the male to female ratio was 2.12:1. One of the hypotheses of why are males more affected than females is because females have a higher estrogen hormone level, much higher than males. Estrogen was found to be associated with the protection against CRC. Estrogens were found to be important in protecting against the initiation and progression of colorectal carcinoma, and this protective effect is most likely facilitated by estrogen receptor $\beta(\operatorname{ER} \beta)$ (Hartman \& Gustafsson, 2010).

The report of Iraqi Cancer Registry (2010) stated that the male to female ratio of patients with colorectal carcinoma was 1.23:1, whereas the present study gave a higher incidence in male patients than female patients. Majid et al. (2009) reported that the male to female ratio was 1.6:1, which is slightly higher than that of the present study, but again it emphasizes that males are more frequently affected than females. AlHumadi (2008) reported a male to female ratio of 1.4:1, which is again in accordance with the present study, clarifying a higher frequency of colorectal carcinoma among male patients.

\section{Site of Colorectal Carcinoma within the Colon}

The recto-sigmoid region location presented $60 \%$ of tumor masses in the current study and $14 \%$ of cases were found in the sigmoid region. In combination, rectum and sigmoid area were responsible for $74 \%$ of cases. This result should be viewed from two points of view. The first is that screening programs for colonic tumors should make use of colonoscopy procedure as a gold standard test. The second point of view is the question: why do colonic tumors predominantly involve the rectum and sigmoid region? The suggested pathogenesis of colorectal carcinoma is where the answer could be found. It is now well known that most of these malignant tumors arise from premalignant precursors called adenomas (Fredericks et al., 2015). These colon adenomas are categorized into three main types: tubular, villous and tubule-villous adenomas (Qasim et al., 2012). Multistep genetic and epigenetic mutations occur leading to the progression of villous adenomas to adenocarcinoma (Migliore et al., 2011).

Majid et al. (2009) observed that the rectum was responsible for 35\% of the locations of colorectal tumors, similar to the results of the current study. The majority of colorectal tumors involved the rectal region and accounted for about 35\% (Abdulhussain \& Othman, 2013); such results were obtained in the current study.

\section{Grade and Stage of Colorectal Carcinoma}

The majority of colorectal carcinoma (56\%) had a well differentiated grade I histological pattern in this study. It is known that malignant tumors of the large intestines are well-to-moderately differentiated adenocarcinomas, secreting different amounts of mucin (Rosai \& Ackerman, 2011). Others studies showed that the majority of colorectal carcinoma cases (64\%) were well differentiated grade I lesions (Mahmodlou et al., 2012). The current study showed similar results. The present study showed that most of the patients enrolled in the current study $(66 \%)$ had stage II disease. This can be attributed to the fact that early stage (carcinoma in situ and stage I disease) tumors are often not diagnosed due to lack of proper screening programs like colonoscopy and imaging techniques which can be applied on high risk groups. Most of the patients in the present study had stage II disease is in agreement with many authors: Ali et al. (2014), Abu-Helalah et al. (2013), Abdulhussain \& Othman (2013), and Mahmodlou et al. (2012). The majority of the poorly differentiated cases presented at earlier stages of the disease for tumor differentiation, which may be due to non-expectation of the disease.

\section{Conclusions}

From the achieved results of this study, the following can be concluded:

There was a significant association between stage of disease and gender of patients and female patients are more liable to advanced stage disease than male patients. Iraqi patients with CRC were at younger ages and had more advanced stages of the disease, presenting mostly in a poorly differentiated type and extra advanced stage than in older patients. These findings make it necessary to conduct a comprehensive awareness program for the control of this type of tumor.

\section{References}

1. Ferlay, J., Soerjomataram, I., Ervik, M., Dikshit, R., Mathers, C. (2013): GLOBOCAN (2012) V1.0, cancer incidence and mortality worldwide: IARC Cancer Base No. 11. International Agency for Research on Cancer.

2. Cunningham, D., Atkin, W., Lenz, H.J., Lynch, H.T., Minsky, B., Nordlinger, B. and Starling, N. (2010): Colorectal cancer. The Lancet. 375 (9719):1030-1047.

3. Zarychanski, R., Chen, Y., Bernstein, C. N. and Hébert, P. C. (2007): Frequency of colorectal cancer screening and the impact of family physicians on screening behaviour. Canadian Medical Association Journal 177(6): 593-597.

4. Jasperson, K.W., Tuohy, T.M., Neklason, D.W. and Burt, R.W. (2010) Hereditary and familial colon cancer. Gastroenterology 138(6): 2044-2058.

5. Migliore, L., Migheli, F., Spisni, R. and Coppedè, F. (2011): Genetics, cytogenetics, and epigenetics of colorectal cancer. BioMed Research International 2011.

6. Michels, K.B., Giovannucci, E., Joshipura, K.J., Rosner, B.A., Stampfer, M.J., Fuchs, C.S., Colditz, G.A., Speizer, F.E. and Willett, W.C. (2000) Prospective study of fruit and vegetable consumption and incidence of colon and rectal cancers. Journal of the National Cancer Institute 92(21): 1740-1752.

7. Terry, P., Ekbom, A., Lichtenstein, P., Feychting, M. and Wolk, A. (2001) Long-term tobacco smoking and colorectal cancer in a prospective cohort study. International Journal of Cancer 91(4): 585-587.

8. Church, J. and Simmang, C. (2003) Practice parameters for the treatment of patients with dominantly inherited colorectal cancer (familial adenomatous polyposis and hereditary nonpolyposis colorectal cancer). Diseases of the Colon \& Rectum 46(8): 1001-1012.

9. Hamilton, S. R., Aaltonen, L. A., Cancer, I. A. f. R. o. and Organization, W. H. (2000) Pathology and genetics of tumours of the digestive system. IARC press Lyon.

10. Hamilton S.R., Bosman F.T., Carmeiro F., Hruban R.H. and Boffetta P. (2010) Carcinoma of the colon and rectum in: WHO classification of tumors of the digestive system. Thesis MD, eds. Lyon: IARC press. 134-46.

11. Compton, C.C., Fielding, L.P., Burgart, L.J., Conley, B., Cooper, H.S., Hamilton, S.R., Hammond, M.E.H., Henson, D.E., Hutter, R.V. and Nagle, R.B. (2000) Prognostic factors in colorectal cancer. Arch Pathol Lab Med 124 (7): 979-994. 
12. Compton, C.C., Committee, C. and Pathologists, C. o. A. (2000) Updated protocol for the examination of specimens from patients with carcinomas of the colon and rectum, excluding carcinoid tumors, lymphomas, sarcomas, and tumors of the vermiform appendix: a basis for checklists. Archives of Pathology and Laboratory Medicine 124(7): 1016-1025.

13. Leopoldo, S., Lorena, B., Cinzia, A., Luciana, B. A., Renato, C., Antonio, M., Carlo, S., Cristina, P., Stefano, C. and Maurizio, T. (2008) Two subtypes of mucinous adenocarcinoma of the colorectum: clinicopathological and genetic features. Annals of surgical oncology 15(5): 1429-1439.

14. Kang, H., O'Connell, J.B., Maggard, M.A., Sack, J. and Ko, C.Y. (2005) A 10-year outcomes evaluation of mucinous and signet-ring cell carcinoma of the colon and rectum. Diseases of the Colon and Rectum 48(6): 1161-1168.

15. Makino, T., Tsujinaka, T., Mishima, H., Ikenaga, M., Sawamura, T., Nakamori, S., Fujitani, K., Hirao, M., Kashiwazaki, M. and Masuda, N. (2006) Primary signet-ring cell carcinoma of the colon and rectum: report of eight cases and review of 154 Japanese cases. Hepato-gastroenterology 53(72): 845-849.

16. Chen, J.-S., Hsieh, P.-S., Chiang, J.-M., Yeh, C.-Y., Tsai, W.S., Tang, R., Changchien, C.-R. and Wu, R.-C. (2010) Clinical outcome of signet ring cell carcinoma and mucinous adenocarcinoma of the colon. Chang Gung Med J 33(1): 51-57.

17. Murphy, G., Devesa, S.S., Cross, A.J., Inskip, P.D., McGlynn, K.A. and Cook, M.B. (2011) Sex disparities in colorectal cancer incidence by anatomic subsite, race and age. International journal of cancer 128(7): 1668-1675.

18. Wong, R.J. (2010) Marked variations in proximal colon cancer survival by race/ethnicity within the United States. Journal of clinical gastroenterology 44(9): 625-630.

19. Alexander, D.D., Waterbor, J., Hughes, T., Funkhouser, E., Grizzle, W. and Manne, U. (2007) African-American and Caucasian disparities in colorectal cancer mortality and survival by data source: an epidemiologic review. Cancer biomarkers: section A of Disease markers 3(6): 301.

20. Roy, H.K. and Bianchi, L.K. (2009) Differences in colon adenomas and carcinomas among women and men: potential clinical implications. Jama 302(15): 1696-1697.

21. Zisman, A. L., Nickolov, A., Brand, R. E., Gorchow, A. and Roy, H. K. (2006) Associations between the age at diagnosis and location of colorectal cancer and the use of alcohol and tobacco: implications for screening. Archives of internal medicine 166(6): 629-634.

22. American Cancer Society. (2015) Cancer Facts and Figures. Atlanta, Ga: American Cancer Society. Inflamm Bowel Dis., 16:1097-1107.

23. Al-Jubori, M.B. (2015) Immunohistochemical and Molecular Study of Colorectal Cancer Patients; Ph.D. Thesis, College of Science, Kufa University, Iraq.

24. Iraqi Cancer Registry (2009) Republic of Iraq, Ministry of Health cancer board.

25. Ameen, S.T., Mahmood, E.Sh., Hasan, A.Sh., and Al-Ajeeli, K.S.. (2014) Detection of human cytomegalovirus in iraqi colorectal cancer patients. International Journal of Development Research. 4(3): 688-692.
26. Aykan, N. F., Yalçın, S., Turhal, N. S., Özdoğan, M., Demir, G., Özkan, M., Yaren, A., Camc1, C., Akbulut, H. and Artaç1, M. (2015) Epidemiology of colorectal cancer in Turkey: A cross-sectional disease registry study (A Turkish Oncology Group trial). Turk J Gastroenterol 26: 145-153.

27. Kaiser, J.C., Meckbach, R. and Jacob, P. (2014) Genomic instability and radiation risk in molecular pathways to colon cancer.

28. Busby, C., Hamdan, M. and Ariabi, E. (2010) Cancer, infant mortality and birth sex-ratio in Fallujah, Iraq 2005-2009. International journal of environmental research and public health 7(7): 2828-2837.

29. Hartman, J. and Gustafsson, J.- $\AA$. (2010) Estrogen receptors in colorectal cancer: goalkeepers, strikers, or bystanders? Cancer Prevention Research 3(8): 897-899.

30. Iraqi Cancer Registry, (2010) Republic of Iraq, Ministry of Health cancer board.

31. Majid, T.A, Shakir, W.M. and Mahmmod, A.S. (2009) Colorectal Carcinoma Presentation and Management. The Iraqi Postgraduate Medical Journal. 8(3): 7-12.

32. Al-Humadi, A. H. (2008) Epidemiology of Colon and Rectal Cancer in Iraq. World Journal of Colorectal Surgery. 1(1): 122.

33. Fredericks, E., Dealtry G. and Roux S. (2015) Molecular aspects of Colorectal Carcinogenesis: A Review. J Cancer Biol Res. 3(1): 1057.

34. Qasim, B.J., Ali, H.H. and Hussein, A.G. (2012) Immunohistochemical expression of PCNA and CD34 in colorectal adenomas and carcinomas using specified automated cellular image analysis system: A clinicopathologic study. Saudi journal of gastroenterology: official journal of the Saudi Gastroenterology Association 18(4) 268.

35. Migliore, L., Migheli, F., Spisni, R. and Coppedè, F. (2011) Genetics, cytogenetics, and epigenetics of colorectal cancer. BioMed Research International 2011.

36. Abdulhussain, S.S. and Othman, O.H. (2013) Epidemiological study of colorectal and rectal carcinoma in Kirkuk city. Iraqi journal of gastroenterology, 6(1): 33-45.

37. Rosai, J. and Ackerman S. (2011) Surgical Pathology. $1^{\text {st }}$ ed. Philadelphia, Mosby.

38. Mahmodlou, R., Mohammadi, P. and Sepehrvand, N. (2012) colorectal cancer in northwestern Iran. ISRN gastroenterology 2012.

39. Ali, R.H., Marafie, M.J., Bitar, M.S., Al-Dousari, F., Ismael, S., Haider, H.B., Al-Ali, W., Jacob, S. P. and Al-Mulla, F. (2014) Gender-Associated Genomic Differences in Colorectal Cancer: Clinical Insight from Feminization of Male Cancer Cells. International journal of molecular sciences 15(10): 1734417365.

40. Abu-Helalah, M.A., Alshraideh, H.A., Al-Hanaqta, M.M. and Arqoub, K.H. (2014) Quality of life and psychological wellbeing of colorectal cancer survivors in Jordan. Asian Pacific journal of cancer prevention: APJCP 15(18): 7653-7664. 